\title{
Detection of Various $\beta$-Lactamases and their Co-production by Novel Disc Placement method among Gram Negative Bacilli isolates from patients with Spontaneous Bacterial Peritonitis
}

\author{
Kunal Bansal $^{1}$, Ritu Aggarwal ${ }^{2 *}$, H K Aggarwal ${ }^{3}$, Aparna Yadav', \\ Priyanka Yadav and Priyanka Bansal ${ }^{5}$ \\ ${ }^{1}$ HCMS-I,Rohtak, Haryana, India \\ ${ }^{2}$ Department of Microbiology, Rohtak, Haryana, India \\ ${ }^{3}$ Department of Medicine, Rohtak, Haryana, India \\ ${ }^{4}$ Department of Microbiology, Rohtak, Haryana, India \\ ${ }^{5}$ Department of Anaesthesiology \& Critical care, Rohtak, Haryana, India \\ PGIMS, Rohtak, Haryana, India \\ *Corresponding author
}

\begin{tabular}{|l} 
K e y w o r d s \\
SBP, MDR, $\beta$ - \\
lactamases, ESBL, \\
AmpC, MBL,Novel \\
disc panel.
\end{tabular}

Keywords

SBP, MDR, $\beta$ -

AmpC, MBL,Novel

disc panel.

20 January 2020

\section{A B S T R A C T}

Gram-negative bacilli (GNB) are most frequently isolated bacteria from ascitic fluid aspirate of patients with Spontaneous bacterial peritonitis (SBP). Aetiology of SBP has been changing in recent years with increased involvement of multidrug resistant (MDR) bacteria as a result of production of various $\beta$-lactamases. The present study was done for detection of different $\beta$-lactamases and their co-existence by noveldisc placement method among GNB isolates from patients with SBP. Disc panel containing ceftazidime (CA), ceftazidime/tazobactam (CA/TZ), cefepime (CFP), ceftazidime/ tazobactam/ cloxacillin (CA/TZ/CLOX), imipenem (IMP) and Mercaptopropionic acid (MPA) was used. Pureextended spectrum $\beta$-lactamase (ESBL) production was found in 18 of 42 isolates $(42.86 \%)$. Maximum ESBL positive isolates were found in E.coli (13 out of 28 isolates).Pure AmpC production was found in 6 of 42 isolates (14.28\%). Metallo- $\beta$ lactamases (MBL) production was found in only 2 of 42 isolates (4.76\%). Co-production of ESBL+ AmpC was seen in 3 of 42 isolates (7.145). All ESBL positive isolates showed multidrug resistance pattern. Detection of $\beta$-lactamase producing isolates will provide knowledge regarding resistance pattern of bacterial strains in a particular geographical area. This will further help promote appropriate and judicious use of antibiotics. 


\section{Introduction}

SBP is a common and serious complication of patients with liver cirrhosis and ascites, despite the absence of an obvious surgically treatable intra-abdominal source of infection $^{1,2,3}$. It often develops insidiously and may remain unrecognized. GNB are the most frequently isolated bacteria from the ascitic fluid aspirates of patients with SBP. As per European Association for the Study of the Liver (EASL) and Infectious Diseases Society of America (IDSA) guidelines, thirdgeneration cephalosporins (including cefotaxime and ceftriaxone) are recommended for empirical first-line therapy of patients with SBP. Amoxycillin-clavulanic acid and quinolones (ciprofloxacin, ofloxacin) are the other effective alternatives. ${ }^{2,4-6}$ Recent studies conducted in India and worldwide have indicated a low response rate to thirdgeneration cephalosporins in patients with SBP.The rates of cephalosporin resistance in patients with SBP has been shown to be 21$45 \%$. $^{2,7,8}$

Aetiology of SBP has been changing in the recent years with the increased involvement of multiple antibiotic resistant bacteria as a result of production of various $\beta$-lactamases by them. According to the pattern of antibiotic consumption, great differences exist in antibiotic sensitivity and resistance among various countries. Currently, information regarding the spectrum of the involved bacteria and the pattern of antibiotic resistance in developing countries is scarce. So knowledge about the local epidemiological pattern of prevalent bacterial agents and their antibiotic resistance would be necessary for formulation of institutional antibiotic policy. ${ }^{2}$, ${ }^{3}$, ${ }^{7}$ Hence it was thought worthwhile to conduct a study to detect various $\beta$-lactamases and their co-production among the GNB isolated from cases of SBP.
Various authors have recommended several methods for phenotypic detection of $\beta$ lactamases, but even today there are no perfect phenotypic methods for their detection. $^{9-18}$ Clinical and Laboratory Standards Institute (CLSI) has issued guidelines only for the confirmation of ESBL in Escherichia coli, Klebsiella pneumoniae, Klebsiella oxytoca and Proteus mirabilis and not for AmpC and MBL $\beta$-lactamases. ${ }^{14,19}$

The CLSI recommended phenotypic confirmation test, fails to detect ESBL in presence of AmpC, as clavulanic acid which is used in the test, may induce high level expression of AmpC, masking synergy arising from the inhibition of an ESBL. This leads to false negative results in the ESBL detection test causing resistance to the $3^{\text {rd }}$ generation cephalosporins as well as to the $3^{\text {rd }}$ generation cephalosporins+clavulanic acid. As a result of this, treatment of clinical conditions caused by such strains is adversely affected. So, even if ESBL is present, it will not be detected and it may result in false negative result.

Tazobactam and sulbactam are much less likely to induce AmpC $\beta$-lactamases and are therefore preferable inhibitors for ESBL detection test. Another possible solution is to include cefepime as an ESBL screening agent. High-level AmpC expression has minimal effect on the activity of cefepime, making this drug a more reliable detection agent for ESBL even in the presence of an AmpC $\beta$ lactamase. $^{14,15,18}$

Boronic acid and cloxacillin are the two most commonly used chemical agents, for the detection of AmpC enzymes. Several authors have preferably used cloxacillin over boronic acid, as boronic acid has been reported to inhibit Klebsiella pneumoniae carbapenemase (KPC) enzymes and sometimes other ESBLs and Oxacillinase-12 (OXA-12) enzymes. ${ }^{11}$ 
Most investigators have recommended the use of imipenem over ceftazidime for the detection of MBL enzymes, as the isolates may have additional ceftazidime resistance mechanism such as ESBL and AmpC production. Among the chelating agents MPA is preferred over others because it is able to distinguish $\mathrm{MBL}$ producing strains more distinctively from other serine $\beta$-lactamases (AmpC and ESBL) producing strains. ${ }^{13,16}$

After extensive review of the work done by various authors on $\beta$-lactamase phenotypic detection methods, a novel disk placement method was designed to detect various $\beta$ lactamases and their co-production.

\section{Materials and Methods}

The present study was conducted in the Departmentsof Microbiology and Medicine, Pt. B.D. Sharma, PGIMS, Rohtak over a period of one year.

\section{Method of detection of various $\beta$ - lactamases}

All the GNB isolates were processed for the determination of $\beta$-lactamase production by novel disc placement method. This was done by preparing 0.5 McFarland standard suspension of the organism to be tested in broth. It was inoculated on Mueller-Hinton Agar (MHA) plate of $100 \mathrm{~mm}$ diameter and was allowed to dry for 3-10 minutes.

Briefly, five $\mu \mathrm{l}$ of freshly prepared cloxacillin (procured from Aristo Pharmaceuticals Pvt. Ltd., Daman) was added to each disc of ceftazidime/tazobactam (CA/TZ) (30 $\mu \mathrm{g} /$ $10 \mu \mathrm{g}$.). The final concentration of cloxacillin on each disc was $200 \mu \mathrm{g}$. The discs were allowed to dry for 60 minutes and then used immediately.

All the discs were placed in the MHA plate in the specified order as shown in the figure 1. Various antibiotic discs that were used for the tests are described below:-

ESBL detection was done by using discs of ceftazidime (CA) $(30 \mu \mathrm{g})$, ceftazidime/tazobactam (CA/TZ) $(30 \mu \mathrm{g} / 10 \mu \mathrm{g})$ and cefepime (CFP) $(30 \mu \mathrm{g})$. Disc of CA/TZ was kept in the centre and disc of CA was kept at a distance of 15 $\mathrm{mm}$ from CA/TZ. ${ }^{18,19}$ On the other side of $\mathrm{CA} / \mathrm{TZ}$ a disc of CFP was kept at a distance of $20 \mathrm{~mm} .^{15}$

MBL detection was done by using imipenem (IMP) $(10 \mu \mathrm{g})$ and MPA (was prepared by pouring $3 \mu \mathrm{l}$ of undiluted Mercaptopropionic acid (MPA) over sterile blank discdiscs. Two discs were kept at a distance of $10 \mathrm{~mm}$ from each other. $^{13,16}$

AmpC $\beta$-lactamases were detected by use of CA/TZ $(30 \mu \mathrm{g} / 10 \mu \mathrm{g})$ and ceftazidime/ tazobactam/ cloxacillin (CA/TZ/CLOX) $(30 \mu \mathrm{g} / 10 \mu \mathrm{g} / 5 \mu \mathrm{l})$. Disc of CA/TZ/CLOX was kept independently without any relation to other drugs. ${ }^{14}$

All plates were incubated at $18-24 \mathrm{hrs}$. at $35 \pm 2{ }^{\circ} \mathrm{C}$ in ambient air. The following day all the zones of inhibition were read and recorded. For quality control, ATCC control strains of $S$. aureus ATCC ${ }^{\circledR} 25923$, E. coli ATCC $^{\circledR} 25922$ and $P$. aeruginosa ATCC $^{\circledR}$ 27853 and Klebsiella pneumoniae ATCC $^{\circledR}$ 700603 were used.

\section{Interpretation}

ESBL :- A more than five $\mathrm{mm}$ increase in the zone of CA in presence of $\mathrm{TZ}$ was indicative of ESBL production. ${ }^{18,}{ }^{19}$ Any enhancement in zone of CFP towards the disk of CA/TZ was indicative of ESBL production. $^{15}$ 
MBL:-Any clear extension of the inhibition zone of IMP towards the MPA disc was interpreted as positive result. ${ }^{13,16}$

AmpC :- A more than four $\mathrm{mm}$ increase in the zone of CA/TZ in the presence of CLOX was considered as positive for AmpC enzyme. ${ }^{14}$

ESBL and AmpC co-producers:-A more than five $\mathrm{mm}$ increase in the zone diameter of CA disc in presence of $\mathrm{TZ}$ and further increase in the diameter of more than four $\mathrm{mm}$ in CA/TZ/CLOX was indicative of coproduction of ESBL and AmpC. ${ }^{18}$

Antimicrobial susceptibility testing (AST) of all GNB, isolated from 100 ascitic fluid samples collected aseptically with a needle and syringe from cirrhotic patients with SBP was performed by Kirby-Bauer disc diffusion method on MHA procured from Hi- Media, Mumbai using CLSI criteria. ${ }^{19,}{ }^{20}$ Following antimicrobials with their disc concentration in parenthesis were tested. (Table 1)

\section{Statistical analysis}

Entiredata was collected and entered using Microsoft Office Excel worksheet and exported to Statistical Package for Social Studies (SPSS software- latest version) and analysed. Data was compiled in tabulated manner and was expressed as percentage.

\section{Results and Discussion}

All 42 GNB isolates recovered from 100 cases of SBP were tested for detection of ESBL, AmpC, MBL and their co-production by a novel disc placement method and were also tested for routine antimicrobial susceptibility testing.
Pure ESBL production was found in 18 out of 42 isolates $(42.86 \%)$. It was found in 13 out of a total of 28E.coli isolates. One Acinetobacter spp. which was isolated was also pure ESBL producer. This was followed by Proteus spp.(50\%), E.coli (46.1\%), Citrobacter spp. (33\%), Klebsiella spp. (25\%) and P.aeruginosa (25\%). Pure AmpC production was found in 6 of 42 isolates $(14.28 \%)$ and was found in $33.33 \%$ Citrobacter spp., $25 \%$ Klebsiella spp., $14.28 \%$ E. coli. It was absent in P.aeruginosa, Acinetobacter spp. and Proteus spp. Pure MBL production was found in only 2 of 42 isolates $(4.76 \%)$ and was seen only in E.coli (7.14\%).

Co-production of ESBL+ AmpC was seen in 3 of 42 isolates (7.145). It was found in only $25 \%$ P. aeruginosa and $7.14 \%$ E.coli. ESBL+ MBL and AmpC + MBL co-production was not seen in any of the isolates. ESBL $+\mathrm{AmpC}$ $+\mathrm{MBL}$ co-production was found in only $2.38 \%$ isolates. It was present in $25 \%$ P.aeruginosa isolates. This isolate was susceptible only to polymyxin B.No mechanism of resistance was found in $28.57 \%$ of isolates and these isolates also didn't show any multidrug resistance. (Table 2)

All ESBL positive isolates showed multidrug resistance pattern. Only cefepime, piperacillin/ tazobactam and imipenem were $100 \%$ effective drugs in vitro. Resistance to all other drugs ranged from $11.11 \%$ to 100\%. (Table 3) AmpC producing isolates were multidrug resistant. Cefepime and carbapenems were the two most effective drugs (100\%). Resistance to all other drugs ranged from $16.67 \%$ to $100 \%$. (Table 4) In our study, all MBL producing $E$. coli isolates were $100 \%$ multidrug resistant to all drugs except aztreonam to which all the isolates were $100 \%$ sensitive. ESBL+ AmpC + MBL co-production was seen only in P.aeruginosa and this isolate was pandrug resistant except for polymyxin $\mathrm{B}$. 
$\beta$-lactamase producing organisms are among the fastest growing problems in the area of infectious diseases. Major ESBL producing strains are $K$. pneumoniae, $K$. oxytoca and $E$. coli. They are plasmid mediated and are easily transferable among different bacteria. These plasmids also carry genes for resistance to other non $\beta$-lactam antibiotics. Most frequently, co-resistances are seen among aminoglycosides, fluoroquinolones, tetracyclines, chloramphenicol and trimethoprim-sulfamethoxazole. That's why treating multidrug resistant infections pose a big therapeutic challenge. ${ }^{21}$

In the present study, a novel disc placement method was used for the simultaneous detection of various $\beta$-lactamases and their co-production among the GNB. This method saved time as well as resources in comparison to other studies where detection of different enzymes was carried out separately. 22,23 , ${ }^{24}$ Rawat et $a l^{14}$ employed a novel template for disc placement for the detection of different classes of $\beta$-lactamases in a single isolate, but with more number of discs in comparison to our study.

Out of a total of 42 GNB isolates, 18(42.86\%) were pure ESBL producers. Various studies in different parts of India also report wide range of ESBL production. In Poorva Mathur et $a l^{25}$ study from AIIMS New Delhi, 68\% were found to be ESBL producers. Similarly, G Revathi from UCMS Delhi reported 53\% ESBL positivity from different clinical isolates of GNB. ${ }^{26}$ Ashwin $\mathrm{N}$ Ananthakrishnan et $a l^{27}$ from JIPMER Pondicherry found $20.5 \%$ of their isolates to be ESBL producers. Aggarwal et $a l^{28}$ from Rohtak in 2009 reported ESBL production in $36 \%$ of multidrug resistant (drug resistance to $\geq 3$ drugs) isolates recovered from urine samples. Varsha et $a l^{15}$ from Chandigarh in 2005-06 reported $87.5 \%$ ESBL positivity from pus and body fluids. Rawat et al., ${ }^{14}$ from Uttarakhand in 2013 detected pure ESBL in $16.3 \%$ isolates. Kaur et al., ${ }^{81}$ has reported in 2013$14,66.1 \%$ of isolates as ESBL producers. Divya et al., ${ }^{22}$ in 2016 in Tamil Nadu reported $24 \%$ of isolates as ESBL producers.

The tendency of ESBL production differs for different species of Enterobacteriaceae and non-fermenters. In the present study, maximum number of ESBL positive isolates was found in E.coli (13 out of 28 isolates). ESBL production was found to be highest in Acinetobacter spp. (100\%) followed by Proteus spp.(50\%), E.coli (46.1\%), Citrobacter spp.(33\%), Klebsiella spp.(25\%) and P.aeruginosa (25\%).

Purva Mathur et al., ${ }^{25}$ from AIIMS, New Delhi reported ESBL production of $80 \%$ in Klebsiella spp. and Acinetobacter spp., 64\% in $P$. aeruginosa, $63 \%$ in Citrobacter spp., 61\% in E.coli, 53\% in Proteus spp. and 29\% in Enterobacter spp. Ashwin N. Anathakrishnan et al., ${ }^{27}$ from JIPMER Pondicherry, reported ESBL production in $100 \%$ Citrobacter spp., $58.06 \%$ E. coli, $57.14 \%$ of Enterobacter spp. and $43.75 \%$ of K. pneumoniae.

Varsha et al., ${ }^{15}$ from Chandigarh, found ESBL production in all E.coli and $81.25 \%$ K.pneumoniae. Rawat et $a l^{14}$ from Uttarakhand in 2013 detected pure ESBL in $33.3 \%$ Proteus spp., $24 \%$ E.coli, $13 \%$ P.aeruginosa and 9\% Klebsiella spp. isolates. Kaur et $a l^{29}$ from Jalandhar in 2013-14, reported ESBL production in $74.7 \%$ Klebsiella, $\quad 70.7 \% \quad$ E.coli, $\quad 44.4 \%$ Enterobacter, $20 \%$ Proteus and $1.7 \%$ Citrobacter. Divya et al., ${ }^{22}$ in 2016 in Tamil Nadu reported E. coli as the predominant isolate accounting for $(34.3 \%)$ of ESBL production, followed by P.aeruginosa (31.5\%), Klebsiella spp. (19\%) and $A$. baumannii (31\%).

In our study, AmpC $\beta$-lactamases were seen 
in $14.28 \%$ of the isolates. In India, the first study was done by G. Revathi and Simrita Singh from GTB hospital, Delhi reported 4.7\% AmpC production among various isolates. ${ }^{30}$ Manchanda et $a l^{31}$ has reported positivity rate of AmpC $\beta$-lactamase production at $20.7 \%$. Rawat et al., ${ }^{14}$ in 2013 has reported pure AmpC production at $14.1 \%$ among various isolates. Kaur et al., ${ }^{29}$ reported $46.1 \%$ AmpC production. Divya et al., ${ }^{22}$ in 2016 in Tamil Nadu reported AmpC production in $9 \%$ isolate.

The ability to produce AmpC $\beta$-lactamase is variable in different Gram negative bacteria. AmpC production was found in $33.33 \%$ Citrobacter spp., 25\% Klebsiella spp. and $14.28 \%$ E.coli isolates. No AmpC production was detected in P.aeruginosa, Acinetobacter spp. and Proteus spp.. In India, first study done by G. Revathi and Simrita Singh reported AmpC $\beta$-lactamase production in $33.9 \%$ of P.aeruginosa, $30.4 \%$ from Enterobacter spp. and $12.5 \%$ from Citrobacter spp. ${ }^{30}$ Manchanda et al., ${ }^{31}$ reported AmpC $\beta$-lactamase production in $42.86 \%$ of Acinetobacter spp., $33.33 \%$ of K.pneumoniae and Proteus spp., $14.29 \%$ of E. coli, $26.07 \%$ of Citrobacter spp., and $11.11 \%$ of Pseudomonas spp. Rawat et al., ${ }^{14}$ in 2013 reported $54.5 \%$ AmpC in Klebsiella spp., $25 \%$ in Citrobacter spp., $16.6 \%$ in Proteus spp., $7.6 \%$ in E. coli and $6.8 \%$ in Pseudomonas spp. Kaur et al., ${ }^{29}$ in 2014 reported 52.8\% AmpC in Klebsiella spp., 51.2 $\%$ in E.coli, $15 \%$ in Proteus spp. and $11.1 \%$ in Enterobacter spp. Divya et al., ${ }^{22}$ in 2016 in Tamil Nadu reported AmpC production in $15.9 \% \quad$ E.coli followed by $10.8 \% \quad P$. aeruginosa, $6.6 \%$ Klebsiella spp. and $6.8 \%$ A. baumannii respectively.

MBL production in our study was $4.76 \%$ of the total isolates, exhibited only by E.coli. In a 2011 study by Bashir et al $11.66 \%$ of P.aeruginosa produced MBL.Oberoi et $a l^{23}$ in
2013 in Punjabhas reported MBL production in $10.98 \%$ isolates, mainly observed in $K$. pneumoniae $(33.4 \%)$ and $P$. aeruginosa (26.67\%). Divya et $a l^{22}$ in 2016 in Tamil Nadu reported MBL in $1 \%$ isolate.

In our study, ESBL+ AmpC co-production was seen in $7.14 \%$ isolates, mainly in P.aeruginosa (25\%) and E.coli (7.14\%). $\mathrm{ESBL}+\mathrm{MBL}$ and AmpC + MBL coproduction was not seen in our study. A 2013 study from Turkey reported prevalence of ESBL in $46 \%$ isolates, only AmpC in 3\% isolates and production of both of these in $38 \%$ isolates. ${ }^{33}$ Mohanty et $a l^{34}$ in 2008 in New Delhi, reported pure ESBL $61.9 \%$, AmpC $78.7 \%$ and ESBL + AmpC 58.4\%. Oberoi et $a l^{23}$ in 2013 in Punjab, reported $35.16 \%$ ESBL, $5.49 \%$ AmpC, $6.59 \%$ ESBL+AmpC, $8.79 \% \quad \mathrm{ESBL}+\mathrm{MBL}$ and $3.67 \%$ AmpC +MBL co-production. A 2013 study from Pune reported $40.07 \%$ ESBL, 14.8\% AmpC and 9.9\% ESBL+ AmpC from isolates. ${ }^{35}$ Handa et $a l^{36}$ in 2013 in Meerut reported82.76\%ESBL, 40\% AmpC $84.62 \%$ ESBL + AmpC. Another study in 2014 in Karnataka by Doddaiah et $a l^{37}$ reported $85 \%$ ESBL, $10 \%$ AmpC and 33\% ESBL and AmpC co-production. ESBL+AmpC+ MBL co-production was seen in only one $P$. aeruginosa isolate which constituted $2.38 \%$ of the gram negative isolates in our study. In a study conducted by Oberoi et $a l^{23}$, the coproduction of ESBL+ AmpC+ MBL in Gram negative isolates from a tertiary care hospital in Punjab was found to be $19.04 \%$ which was much higher than in our study. Garg et $a l^{24}$ in Rohtak in 2015 reported co-production of all three $\beta$-lactamases in $3 \%$ of isolates. Divya et $a l^{22}$ in 2016 in Tamil Nadu reported coexistence of ESBL and AmpC in 2.5\% isolates, ESBL and MBL co-production was detected in $1 \%$ and AmpC and MBL was observed in $0.2 \%$ isolate. Rawat et $a l^{14}$ did not report any co-production of all three $\beta$ lactamases in any of the isolates. All the rest 
of the isolates in our study didn't have any mechanism of resistance. These isolates also did not exhibit multidrug resistance.

All isolates producing various $\beta$-lactamases in this study were multidrug resistant. ESBL and AmpC $\beta$-lactamases producing organisms exhibited $100 \%$ sensitivity pattern for imipenem and cefepime. Co-resistance to aminoglycosides and fluoroquinolones was also seen, with levofloxacin exhibiting $55.56 \%$ resistance rate for ESBL producers. AmpC producers exhibited $100 \%$ coresistance for cotrimoxazole, aminoglycosides and fluoroquinolones.

Similar results were seen in study by Kaur $e t$ al. ${ }^{29}$ where associated co-resistance was seen with cotrimoxazole (84.2\%), gentamycin $(79 \%)$ and fluoroquinolones (90-93\%). Varsha et $a l^{15}$ demonstrated comparatively high level co-resistance to gentamycin (91.17\%), cotrimoxazole (100\%), ciprofloxacin $(94.91 \%)$ and amikacin (64.28\%). All strains were $100 \%$ sensitive to imipenem.

Table.1 Various antibiotic discs used for AST

\begin{tabular}{|c|c|}
\hline For all GNB other than Pseudomonas spp. & For Pseudomonas spp. \\
\hline 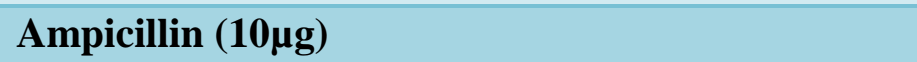 & Cefoxitin $(30 \mu \mathrm{g})$ \\
\hline Amoxicillin/Clavulanic acid $(20 \mu \mathrm{g} / 10 \mu \mathrm{g})$ & Ceftazidime $(30 \mu \mathrm{g})$ \\
\hline Cefotaxime $(30 \mu \mathrm{g})$ & Cefepime $(30 \mu \mathrm{g})$ \\
\hline Ceftriaxone (30 $\mu \mathrm{g})$ & Piperacillin $(100 \mu \mathrm{g})$ \\
\hline 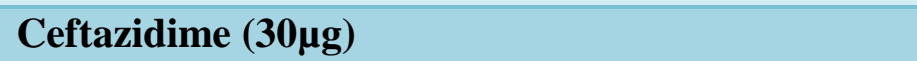 & Piperacillin/ Tazobactam $(100 \mu \mathrm{g} / 10 \mu \mathrm{g})$ \\
\hline Cefepime (30ug) & Levofloxacin $(5 \mu \mathrm{g})$ \\
\hline Piperacillin $(100 \mu \mathrm{g})$ & Tobramycin $(30 \mu \mathrm{g})$ \\
\hline Piperacillin/Tazobactam $(100 \mu \mathrm{g} / 10 \mu \mathrm{g})$ & Amikacin $(30 \mu \mathrm{g})$ \\
\hline Ciprofloxacin $(5 \mu \mathrm{g})$ & Imipenem $(10 \mu \mathrm{g})$ \\
\hline Levofloxacin $(5 \mu \mathrm{g})$ & Ertapenem $(10 \mu \mathrm{g})$ \\
\hline Gentamicin $(10 \mu \mathrm{g})$ & Polymyxin $(300 \mu \mathrm{g})$ \\
\hline Trimethoprim/Sulfamethoxazole $(1.25 \mu \mathrm{g} / 23.75 \mu \mathrm{g})$ & Aztreonam $(30 \mu \mathrm{g})$ \\
\hline \multicolumn{2}{|l|}{ Ertapenem $(10 \mu \mathrm{g})$} \\
\hline \multicolumn{2}{|l|}{ Imipenem $(10 \mu \mathrm{g})$} \\
\hline Aztreonam $(30 \mu \mathrm{g})$ & \\
\hline
\end{tabular}


Table.2 Resistance pattern among various gnb isolates

\begin{tabular}{|c|c|c|c|c|c|c|c|c|c|c|c|c|c|c|}
\hline \multirow{2}{*}{ ק- lactamases } & \multicolumn{2}{|c|}{ E. coli } & \multicolumn{2}{|c|}{$\begin{array}{l}\text { Klebsiella } \\
\text { spp. }\end{array}$} & \multicolumn{2}{|c|}{$\begin{array}{l}P . \\
\text { aeruginosa }\end{array}$} & \multicolumn{2}{|c|}{$\begin{array}{l}\text { Acinetobact } \\
\text { er spp. }\end{array}$} & \multicolumn{2}{|c|}{$\begin{array}{l}\text { Citrobacter } \\
\text { spp. }\end{array}$} & \multicolumn{2}{|c|}{$\begin{array}{l}\text { Proteus } \\
\text { spp. }\end{array}$} & \multicolumn{2}{|c|}{ Total } \\
\hline & No. & $\%$ & No. & $\%$ & No. & $\%$ & No. & $\%$ & No. & $\%$ & No. & $\%$ & No. & $\%$ \\
\hline ESBL & 13 & 46.1 & 1 & 25 & 1 & 25 & 1 & 100 & 1 & 33.33 & 1 & 50 & 18 & 42.86 \\
\hline AmpC & 4 & 14.28 & 1 & 25 & 0 & 0 & 0 & 0 & 1 & 33.33 & 0 & 0 & 6 & 14.28 \\
\hline MBL & 2 & 7.14 & 0 & 0 & 0 & 0 & 0 & 0 & 0 & 0 & 0 & 0 & 2 & 4.76 \\
\hline ESBL+ AmpC & 2 & 7.14 & 0 & 0 & 1 & 25 & 0 & 0 & 0 & 0 & 0 & 0 & 3 & 7.14 \\
\hline ESBL+MBL & 0 & 0 & 0 & 0 & 0 & 0 & 0 & 0 & 0 & 0 & 0 & 0 & 0 & 0 \\
\hline AmpC+MBL & 0 & 0 & 0 & 0 & 0 & 0 & 0 & 0 & 0 & 0 & 0 & 0 & 0 & 0 \\
\hline ESBL+AmpC+MBL & 0 & 0 & 0 & 0 & 1 & 25 & 0 & 0 & 0 & 0 & 0 & 0 & 1 & 2.38 \\
\hline No mechanism & 7 & 25 & 2 & 50 & 1 & 25 & 0 & 0 & 1 & 33.33 & 1 & 50 & 12 & 28.57 \\
\hline Total & 28 & 100 & 4 & 100 & 4 & 100 & 1 & 100 & 3 & 100 & 2 & 100 & 42 & 100 \\
\hline
\end{tabular}

Table.3 Antibiotic sensitivity pattern of pure ESBL producing isolates $(n=18)$

\begin{tabular}{|l|l|l|l|l|l|l|l|}
\hline S.No. & \multirow{2}{*}{ Drug } & \multicolumn{2}{|l|}{ Sensitive } & \multicolumn{2}{l|}{ Intermediate Sensitive } & \multicolumn{2}{l|}{ Resistant } \\
\cline { 3 - 8 } & & Total & $\%$ & Total & $\%$ & Total & $\%$ \\
\hline 1. & Ceftazidime & 0 & 0 & 0 & 0 & 18 & 100 \\
\hline 2. & Cefepime & 16 & 88.89 & 2 & 11.11 & 0 & 0 \\
\hline 3. & Piperacillin & 0 & 0 & 0 & 0 & 18 & 100 \\
\hline 4. & $\begin{array}{l}\text { Piperacillin/ } \\
\text { Tazobactam }\end{array}$ & 15 & 83.33 & 3 & 16.67 & 0 & 0 \\
\hline $\mathbf{5 .}$ & Aztreonam & 0 & 0 & 0 & & & \\
\hline 6. & Levofloxacin & 8 & 44.44 & 0 & 0 & 18 & 100 \\
\hline 7. & Imipenem & 17 & 94.44 & 1 & 0 & 10 & 55.56 \\
\hline 8. & Ertapenem & 13 & 72.22 & 3 & 5.56 & 0 & 0 \\
\hline & & & & & 16.67 & 2 & 11.11 \\
\hline
\end{tabular}


Table.4 Antibiotic sensitivity pattern of pure AMPC producing isolates $(n=6)$

\begin{tabular}{|c|c|c|c|c|c|c|c|}
\hline \multirow[t]{2}{*}{ S.No. } & \multirow[t]{2}{*}{ Drug } & \multicolumn{2}{|c|}{ Sensitive } & \multicolumn{2}{|c|}{ Intermediate Sensitive } & \multicolumn{2}{|c|}{ Resistant } \\
\hline & & Total & $\%$ & Total & $\%$ & Total & $\%$ \\
\hline 1. & Ampicillin & 0 & 0 & 0 & 0 & 6 & 100 \\
\hline 2. & Amoxyclav & 0 & 0 & 0 & 0 & 6 & 100 \\
\hline 3. & Cefotaxime & 0 & 0 & 0 & 0 & 6 & 100 \\
\hline 4. & Ceftriaxone & 0 & 0 & 0 & 0 & 6 & 100 \\
\hline 5. & Ceftazidime & 0 & 0 & 0 & 0 & 6 & 100 \\
\hline 6. & Cefepime & 5 & 83.33 & 1 & 16.67 & 0 & 0 \\
\hline 7. & Piperacillin & 0 & 0 & 0 & 0 & 6 & 100 \\
\hline 8. & $\begin{array}{l}\text { Piperacillin/ } \\
\text { Tazobactam }\end{array}$ & 5 & 83.33 & 0 & 0 & 1 & 16.67 \\
\hline 9. & Aztreonam & 0 & 0 & 0 & 0 & 6 & 100 \\
\hline 10. & Ciprofloxacin & 0 & 0 & 0 & 0 & 6 & 100 \\
\hline 11. & Levofloxacin & 0 & 0 & 0 & 0 & 6 & 100 \\
\hline 12. & Gentamycin & 0 & 0 & 0 & 0 & 6 & 100 \\
\hline 13. & Cotrimoxazole & 0 & 0 & 0 & 0 & 6 & 100 \\
\hline 14. & Imipenem & 6 & 100 & 0 & 0 & 0 & 0 \\
\hline 15. & Ertapenem & 5 & 83.33 & 1 & 16.67 & 0 & 0 \\
\hline
\end{tabular}

Figure.1 Arrangement of various antibiotic discs in novel disc placement method

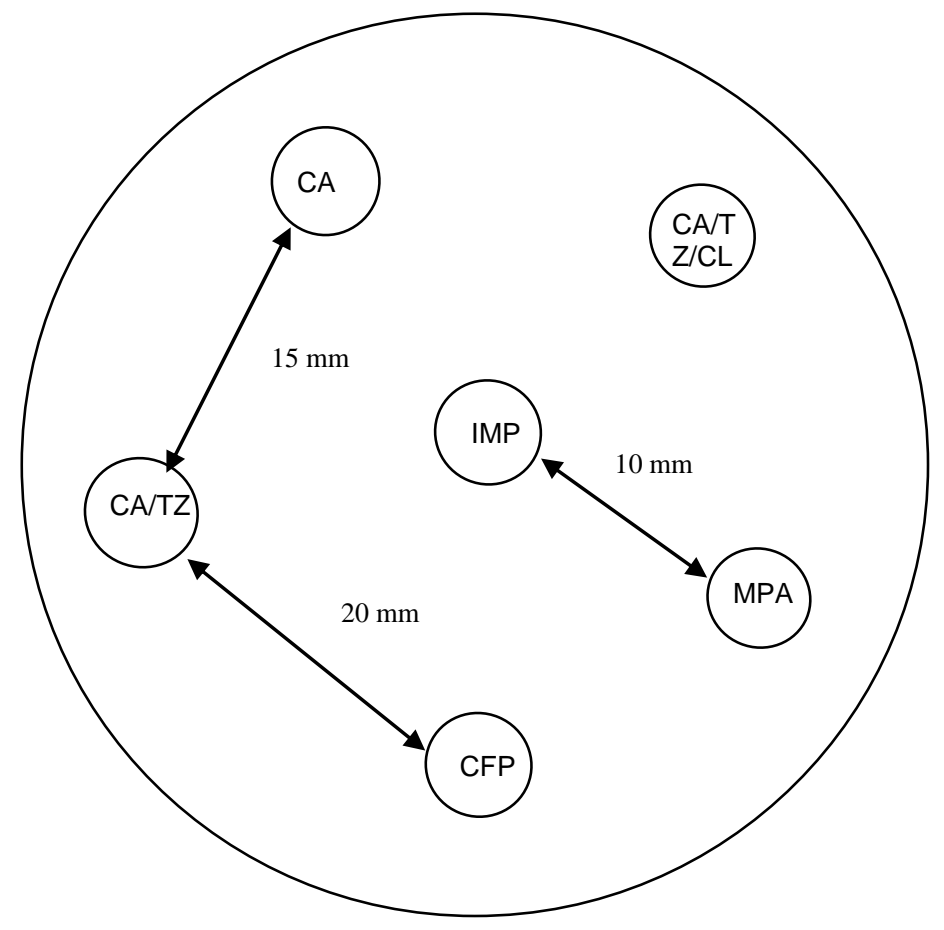


In conclusion, prevalence of $\beta$-lactamases among various species of Enterobacteriaceae and non-fermenters varies geographically. Identification of these enzymes is a major challenge for the clinical microbiology laboratory. Furthermore, these isolates are mostly multidrug resistant. The implication of this fact is significant reduction in antibiotic treatment options thereby leading to deleterious impact on clinical outcome.

If the type of $\beta$-lactamase produced by the pathogen could be detected along with the routine antibiogram before administering the $\beta$-lactam drug to the patient, therapeutic failures can be avoided. Molecular methods are key tools for their detection but are not possible everywhere due to their cost constraints.

Hence, detection of various $\beta$-lactamase positive strains with this compact novel disc method will enable formulation of right antibiotic policy in the hospital by restricting the spread of MDR strains in the community thereby decreasing overall morbidity and mortality. This in turn will further help to decrease the financial burden on the hospital by restricting inappropriate and injudicious use of antibiotics.

\section{References}

1. Such J, Runyon A. Spontaneous bacterial peritonitis. Clin Infect Dis. 1998;27: 66976.

2. Sheikhbahaei S, Abdollahi A, HafeziNejad N, Zare E. Patterns of antimicrobial resistance in the causative organisms of spontaneous bacterial peritonitis: a single centre, six-year experience of 1981 samples. International Journal of Hepatology. 2014:1-6.

3. Bankar S, De A, Baveja S. Study of ascitic fluid for diagnosis of spontaneous bacterial peritonitis in adult patients with cirrhosis.
International Journal of Medical and Applied Sciences. 2014;3:1-9.

4. Ageloni S, Leboffe C, Parente A, Venditti M, Giordano A, Merli M, et al. Efficacy of current guidelines for the treatment of spontaneous bacterial peritonitis in the clinical practice. World Journal of Gastroenterology. 2008;14(17):2757-62.

5. Eckmann C, Dryden M, Montravers P, Kozlov R, SGanga G. Antimicrobial treatment of complicated intra-abdominal infections and the new IDSA guidelines - a commentary and an alternative European approach according to clinical definitions. Eur J Med Res. 2011;16:115-26.

6. European Association for the Study of the Liver. EASL clinical practice guidelines on the management of ascites, spontaneous bacterial peritonitis, and hepatorenal syndrome in cirrhosis. Journal of Hepatology. 2010;53(3):397-417.

7. Tandon P, DelisleA, Topal JE, GarciaTsao G. High prevalence of antibioticresistant bacterial infections among patients with cirrhosis at a US liver centre. ClinGastroenterol and Hepatol. 2012;10:1291-8.

8. Bhat G, Vandana KE, Bhatia S, Suvarna D, Pal CG.Spontaneous ascitic fluid infection in liver cirrhosis: bacteriological profile and response to antibiotic therapy. Indian J of Gastroenterol. 2013;32(5):297-301.

9. Koneman EW, Alled SD, Jand WN, Schreckenberger PL, Winn WC, Jr. Editors. Antimicrobial susceptibility testing. In: Colour Atlas and Textbook of Diagnostic Microbiology. $5^{\text {th }}$ ed. Philadelphia: Lippincott. 1997;785-856.

10. Yu WL, Chuang YC, Jan WR. Extendedspectrum beta-lactamases in Taiwan: epidemiology, detection, treatment and infection control. J MicrobiolImmunol Infect. 2006;39:264-77.

11. Thomson KS. Extended spectrum $\beta$ lactamase, AmpC and carbapenemase 
issues. J Clin. Microbiol. 2010; 48(4):1019-25.

12. Varaiya A, Kulkarni N, Kulkarni M, Bhalekar P, Dogra J. Incidence of metallo beta lactamase producing Pseudomonas aeruginosa in ICU patients. Indian J Med Res. 2008;127:398-402.

13. Arakawa Y, Shibata N, Shibayama K, Kurokawa $\mathrm{H}$, Yagi $\mathrm{T}$, Fujiwara $\mathrm{H}$ and Goto M. Convenient test for screening metallo- $\beta$-lactamases-producing gramnegative bacteria by using thiol compounds. J Clin. Microbiol. 2006;8:403.

14. Rawat V, Singhai M, Verma PK. Detection of different $\beta$-lactamases and their co-existence by using various discs combination methods in clinical isolates of Enterobacteriaceae and Pseudomonas spp.. J Lab Physicians. 2013;5(1):21-5.

15. Gupta V, Singla N, Chander J. Detection of ESBL using third and fourth generation cephalosporins in double disc synergy test. Indian J Med Res. 2007; 126:486-7.

16. Kim SY, Hong SG, Moland ES, Thomson KS. Convenient test using a combination of chelating agents for detection of metallo $\beta$-lactamases in the clinical laboratory. J Clin. Microbiol. 2007;45(9):2798-801.

17. Jayakumar S, Appalaraju B. Prevalence of multi and pan drug resistant Pseudomonas aeruginosa with respect to ESBL and MBL in tertiary care hospital. Ind $\mathrm{J}$ PatholMicrobiol. 2007;50(4):922-5.

18. Tzelepi E, Giakkoupi P, Sofianou D, Loukova V, Kemeroglou A, Tsakris A. Detection of extended-spectrum $\beta$ lactamases in clinical isolates of Enterobacter cloacae and Enterobacter aerogenes. $\mathrm{J} \quad$ ClinMicrobiol. 2000;38(2):542-6.

19. Clinical and Laboratory Standards Insitiute (CLSI). Performance standards for antimicrobial susceptibility testing: Twenty-First Informational Supplement.
CLSI document. M100-S18. CLSI;Wayne,PA,USA;2011.

20. Collee JG, Mles RB, Watt B. Tests for identification of bacteria. In: Collee JG, Fraser AG, Marmon BP, Simmons A editors. Mackie and MacCartney Practical Medical Microbiology, $14^{\text {th }}$ ed. Churchill Livingstone, New York. 1996;131-149.

21. Wathisuwan S, Burgess DS, Lewis II JS. Extended spectrum $\beta$-lactamases. epidemiology, detection and treatment. Pharmacotherapy. 2001;21(8):290-8.

22. Divya.G, Karthika J, Sankar AV. Prevalence of multiple beta lactamases producing gram negative bacilli from various clinical samples in a tertiary care center at Kancheepuram. Int $\mathbf{J}$ of Allied Med Sci and Clin Res. 2016; 4(1):127-35.

23. Oberoi L, Singh N, Sharma P, Aggarwal A. ESBL, MBL, and AmpC $\beta$-lactamase producing superbugs-havoc in intensive care units of Punjab India. J ClinDiagn Res. 2013;7:70-3.

24. Garg M, Sikka R, Deep A, Chaudhary U. The prevalence of co-production of ESBL, AmpC and Metallo- $\beta$-lactamases in Klebsiella Pneumoniae isolates, in a tertiary level health care providing facility in Haryana. Int J Pharm Bio Sci. 2015; 6(2):602-7.

25. Mathur P, Kapil A, Das B, Dhawan B. Prevalence of extended spectrum $\beta$ lactamase producing Gram negative bacteria in a tertiary care hospital. Ind J Med Res. 2002;115:153-7.

26. Revathi G. Detection of extended spectrum $\beta$-lactamases using $\mathrm{E}$ test ESBL strip. Ind J Med Microbiol. 1997;5(2):6971.

27. Ananthakrishnan AN, Kanungo R, Kumar A, Badrinath S. Detection of extended spectrum $\beta$-lactamase producers among surgical wound infections and burn patients in JIPMER. Ind J Med Microbiol. 2000;18(4):160-5. 
28. Aggarwal R, Chaudhary U, Sikka R. Detection of extended spectrum $\beta$ lactamase production among uropathogens. Journal of Laboratory Pysicians.2009; 1(1):7-10.

29. Kaur J, Mahajan G, Chand K, Sheevani and Chopra S. Enhancing phenotypic detection of extended spectrum $\beta$ lactamase in AmpC co-producers by using cefepime and tazobactam. Journal of clinical and diagnostic research. 2016;10(1): 5-8.

30. Revathi G, Singh S. Detection of extended spectrum cephalosporin resistance due to inducible lactamases in hospital isolates. Ind J Med Microbiol. 1997;15(3):113-5.

31. Manchanda V, Singh NP. Detection of AmpC $\beta$-lactamase among Gram negative isolates using a modified three dimensional test. J Antimicrobial Chemotherapy. 2003;51:415-8.

32. Bashir D, Thokar MA, Fomda BA, Bashir G, Zahoor D, Ahmad S and Toboli AS. Detection of metallo-beta-lactamase (MBL) producing Pseudomonas aeruginosa at a tertiary care hospital in Kashmir. African Journal of Microbiology Research. 2011;5(2):164-72.
33. Yilmaz NO, Augus N, Bozcal E, Oner O, Uzel A. Detection of plasmid-mediated AmpC $\beta$-lactamase in Escherichia coli and Klebsiella pneumonia. Indian $\mathrm{J}$ Med Microbiol. 2013;31:294-9.

34. Mohanty S, Gaind R, Ranjan R, Deb M. Use of the cefepime-clavulanate ESBL Etest for detection of extended spectrum $\beta$-lactamase in AmpC co-producing bacteria. J Infect DevCtries. 2010;4(1):249.

35. Grover N, Sahni AK, Bhattacharya S. Therapeutiuc challenges of ESBLs and AmpC $\beta$-lactamase producers in a tertiary care center. Med J Armed Forces India. 2013;69(1):2-4.

36. Handa D, Pandey A, Asthana AK, Rawat A, Handa S, Thakuria B. Evaluation of phenotypic tests for detection of AmpC $\beta$ lactamase in clinical isolates of Escherichia coli. Indian J PatholMicrobiol. 2013;56:135-8.

37. Doddaiah V, Anjaneya D. Prevalence of ESBL, AmpC and carbapenemase among gram negative bacilli isolated from clinical specimens. American J Life Sci. 2014; 2:76-81.

\section{How to cite this article:}

Kunal Bansal, Ritu Aggarwal, H K Aggarwal, Aparna Yadav, Priyanka Yadav, Priyanka Bansal. 2020. Detection of Various $\beta$-Lactamases and their Co-production by Novel Disc Placement method among Gram Negative Bacilli isolates from patients with Spontaneous Bacterial Peritonitis. Int.J.Curr.Microbiol.App.Sci. 9(01): 1327-1338. doi: https://doi.org/10.20546/ijcmas.2020.901.147 